\title{
Making the Case for Disability Innovation: Opportunity at Concrete Change for the Disabled Community
}

\author{
Roubeena Jeetah \\ Mauritius Research and Innovation Council (MRIC), Cybercity Ebène, Mauritius \\ Email: r.rampadaruth@mric.mu,roubeenajr@gmail.com
}

How to cite this paper: Jeetah, R. (2022). Making the Case for Disability Innovation: Opportunity at Concrete Change for the Disabled Community. Open Journal of Social Sciences, 10, 111-125.

https://doi.org/10.4236/jss.2022.102007

Received: December 15, 2021

Accepted: February 12, 2022

Published: February 15, 2022

Copyright $\odot 2022$ by author(s) and Scientific Research Publishing Inc. This work is licensed under the Creative Commons Attribution International License (CC BY 4.0).

http://creativecommons.org/licenses/by/4.0/

\section{(c) (i) Open Access}

\begin{abstract}
Despite enormous progress by governments and non-governmental organizations worldwide for action-research projects and awareness of the public, people with disabilities still face much difficulty in their daily lives due to discrimination, non-visibility and ignorance. Using systematic literature review and observational research as research method, this paper will show that despite disability being a driver for innovation, designing for disability has remained an exclusive, niche and expensive market. This is set to change as more normal-abled persons face the possibility of someday developing symptoms associated with disabilities due to life circumstances and a growing elderly population. The need to include more people with disabilities in the workplace, not only as simple employees, but also as integral members of design, testing and decision-making teams will be emphasized. Some of the wide reaching examples of disability innovation are touched upon. Finally, an overview of disability and disability innovation in Mauritius is also given.
\end{abstract}

\section{Keywords}

Accessible Design, Disability Inclusion, Disability Innovation, Usable Design, Universal Design, Mauritius

\section{Introduction}

\subsection{Research Background: The Whole Spectrum of Disability}

A disability is any continuing condition that restricts everyday activities by substantially reducing capacity of an individual to communicate, interact socially, learn or move. Overcoming the difficulties faced by people with disabilities requires interventions to remove environmental and social barriers along with the 
assistance of appropriate aids and services.

The most common disabilities can be categorized as intellectual, physical and sensory. An intellectual disability is characterized by an IQ below 70. Intellectually challenged people may process information more slowly than others and may experience difficulties with communication and abstract concepts such as money and time. An intellectual disability may be caused by a genetic condition such as Down syndrome, complications during pregnancy and birth, exposure to toxins such as lead or mercury, complications from illnesses such as meningitis, or exposure to alcohol (Aruma, 2021a). Physical disabilities affect a person's physical capacity and/or mobility. Causes of physical disabilities include inherited or genetic disorders, serious illnesses and injuries. Examples include spinal cord injury, epilepsy, multiple sclerosis, muscular dystrophy, dwarfism among others (Aruma, 2021b). Sensory disabilities affect one or more senses: sight, hearing, smell, touch, taste or spatial awareness. Examples include complete blindness or visual impairment (low vision), complete deafness or hearing impairment (partial hearing loss), speech impediments such as Tourette syndrome or sensory processing disorder whereby a person receives the correct sensory information such as touch, sound or movement, but the brain perceives and analyzes the information in an unusual way (Aruma, 2021c).

A person in a wheelchair or carrying a white cane is an undeniable visual indication that he or she is disabled. However, many people worldwide suffer from invisible or hidden disabilities which are not immediately apparent in an individual, e.g. people with visual or auditory disabilities who use contact lenses or discreet hearing aids. Those with joint problems or chronic pain may not use mobility aids on some days or at all. Other examples are people suffering from chronic fatigue, psychiatric disabilities such as major depression and bipolar disorder or chronic illnesses such as renal failure. Around ten per cent of people in the U.S. suffer from a medical condition that could be considered as a type of invisible disability (Disabled World, 2021).

Disabilities can also be differentiated as long-term (permanent), temporary or situational. Temporary disability affects an individual for a short period of time (usually days, weeks, months), with the person eventually recovering fully from the illness or injury. Permanent or long-term disability is an injury or illness from which a person is not usually expected to recover and will most likely live with that disability for the remainder of his or her life (Young Marr Law, 2021). Situational disability is context driven, whereby a person is unable to carry out a task or activity optimally due to some distracting element. Taking the example of hearing, a deaf person, someone suffering from an ear infection and a bartender working in a noisy bar are permanently, temporarily and situationally disabled, respectively (Neves-Charge, 2017).

\subsection{Research Problem}

We are witnessing extraordinary innovations in all spheres of life, from tech- 
nology-driven fields such as nanotechnology, artificial intelligence and robotics to subtler areas such as social innovation. Despite the potential positive impact of innovation on their lives, there is a community of people who are paradoxically often left out of both discussions and implemented solutions: people with disabilities. People with disabilities constitute around fifteen per cent of the world's population, the largest minority (Paudel, Bhandari, \& Bhandari, 2017). The global literacy rate of adults with disabilities is at three per cent and is even lower at one per cent for women with disabilities. Only thirty-five per cent of working-age people with disabilities are currently employed compared to seventy-eight percent of those without disabilities (UN, 2021). Those who are employed and have an invisible disability often keep their status a secret, only thirty-nine per cent of employees with disabilities have disclosed to their manager, twenty-four per cent to their teams and twenty-one per cent to Human Resources (Jain-Link \& Taylor Kennedy, 2019). As the physical, social, digital and biological worlds continue to converge, new technologies and initiatives should increasingly enable people with disabilities to live more comfortable lives.

\subsection{Research Objective}

This paper will shed light on and make the case for Disability Innovation, with concrete examples of what is currently being undertaken worldwide. Moreover, based on the experience gained by the Mauritius Research and Innovation Council (MRIC) as a funding agency for research and innovation projects, the appeal for more research and innovation projects in the field of disability innovation will be made.

\section{The Rationale behind Disability Innovation}

Disability Innovation can be thought as "the creation of novel products, processes, technologies or services or the promotion of novel ways of thinking for implemented solutions that have implications especially for people with disabilities and their entourage."

In 2017, the first institutions exclusively related to disability innovation were established: The Global Disability Innovation Hub in London, England and the Disability Innovation Institute in Sydney, Australia, respectively (Disability Innovation, 2021a; Disability Innovation Institute, 2021). In July 2017, the first Disability Innovation Summit was organized by the Global Disability Innovation Hub (GDI Hubb) hosted at the Queen Elizabeth Olympic Park. Professionals from different areas of science, technology and social science shared their knowledge and practices in order to develop a strategy for the next steps towards inclusive and accessible attitudes, products and services. The Global Disability Innovation Hub has also launched the world's first MSc in the emerging area of Disability Innovation, an MSc in Disability, Design and Innovation in 2018 (Disability Innovation, 2021b).

Although the discourse around disability innovation is relatively new, the link 
between disability and innovation is not. Goggin (2008) explored linkages between disability and innovation. Wise (2012) investigated the impact of technological innovation on child disability. Wolbring (2011) noted seven possible areas of innovation related to people with disabilities. The next subsections provide an update on these articles along with new and exciting developments in the field of disability innovation.

\subsection{Disability as the Driver for Innovation}

"Never underestimate the power of dissatisfaction." Rama Gheerawo, Helen Hamlyn Centre for Design (Ali, 2017).

It may be a lesser known fact, but designing for people with disabilities has indeed unlocked some of the world's major innovations. Throughout history, people with disabilities have been the catalyst behind innovative thinking, leading to a wide-range of useful inventions not only for disabled people but for everyone. The most popular example is text messaging, which was initially invented to help deaf people to communicate, but has since changed the way the entire world connects.

When the Americans with Disabilities Act (ADA) were passed in 1990, the concept of access for everyone became enshrined as a human right. One of the outcomes was the fitting of ramps in and around the built environment on streets and footpaths. Luggage and pram manufacturers saw an opportunity and thus began producing wheeled products, which have since become indispensable (Rose, 2016). Many everyday products evolved from technology developed by or for people with disabilities. Other everyday products designed for the "norm" are later enhanced to be used by people with disabilities. Other products are designed in parallel: uses are found for both specialized assistive technology and in everyday products (Rose, 2016).

This is how it usually goes: a person has a disability that prevents them from performing a task. They (or someone close to them) then devise a solution that enables any person with the specific disability to perform the task. The solution proves so useful that others later adopt and innovate atop the solution, forgetting it was ever associated with accessible design in the first place: the first typewriter allowing a blind woman to write letters leading to computer keyboards; work on hearing devices by Alexander Graham Bell leading to the first patent of a phone, etc. (Steenhout, 2018). The background-blurring feature in video conference calls was developed by a deaf software engineer to facilitate lip-reading. This has proved to be useful during the coronavirus pandemic for people juggling working from home and doing online meetings concurrently with childcare or messy home settings (Daehn \& Croxson, 2021). All of the above are examples of accessible design, whereby the needs of people with disabilities are specifically considered during the design process, while keeping accessibility (the characteristic that products, services, and facilities can be independently used by people with a variety of disabilities) requirements in mind. 
Another approach through which innovation for the disabled community can be achieved exists. Some believe that products and services should be designed with a view that they could be used by a maximum number of diverse individuals, hence universal design which advocates for "the design of products and environments to be usable by all people, to the greatest extent possible, without the need for adaptation or specialized design" (Mace, 1985). Universally designed products and services benefit everyone: people with diverse disabilities as well as able-bodied people of all age, gender, race, status, culture, etc. For example, doors that open automatically upon sensing the presence of someone are useful for a person using a wheelchair as well as parents with baby strollers (DO-IT, 2021).

\subsection{Designing for Disability: Not So Exclusive Anymore}

"Products that are well designed, they work for everyone." Charlotte V. McClain-Nhlapo, World Bank Group (Ali, 2017).

People with disabilities encounter problems in their daily lives because they are living in a world that has been designed for people with a different set of capabilities from them. It is regretful that people design for the majority because they want to reach scale and sell as much as possible. There is also ignorance and a lack of awareness in companies as decision-makers often do not experience the effects of disability first-hand. Investors do not inject money into the sector due to the supposed niche and risky market. As a result, assistive technology and other products and services for people with disabilities are often prohibitively expensive because of the limited number of consumers. Moreover, disability as a sector has not received the focus that it deserves; it is not 'sexy' to work in disability, which is mostly under the purview of not-for-profit organizations and charities (Dawood, 2019). All of this stands to change.

As the life expectancy of each generation grows, the number of elderly people who will face a loss of mobility and deteriorating health will skyrocket. Disability is, however, not exclusive to elderly people. Nobody is immune to a disability (Verdon, 2017). Other ways that make disability a concern for everyone:

- Car and workplace accidents;

- Contracting disease and disease latency;

- Lifestyle issues increasing propensity for disability through obesity;

- Youthful and any life misadventures, really;

- Disabled army veterans, etc.

Taking the example of army veterans, there are currently 3.8 million of them dealing with a disability in the US. Challenge America: Makers for Veterans (CAMVETS) is a 3-day intensive make-athon where teams of designers, engineers and other experts work together to create innovative solutions to the specific challenge of their injured Veteran team member. Strategic partners are then identified to develop and scale viable solutions, making them accessible to thousands of Veterans and other disabled persons facing similar challenges (Challenge America, 2019). 
It needs to be emphasized that improving design for disability benefits people without disabilities as much as people with disabilities. It is in the mundane, ordinary things that we take for granted: people using a lift instead of the stairs because they are tired or people watching films with the subtitles turned on when the kids are sleeping nearby (Ali, 2017). Procter \& Gamble (P \& G) redesigned its Herbal Essences' bottles featuring tactile marks that help people distinguish between them by touch: stripes on shampoo and circles on conditioner. The marks help anyone, from those who wear glasses or contact lenses and have blurry vision in the shower to blind and visually impaired people (Dawood, 2019).

Disability innovation provides an ever-expanding step into the world of business. Investors are missing huge opportunities by ignoring the disability community, a group that wants to spend money is being ignored simply by a lack of a map or a safe, easy way to travel or a lack of consideration on the part of companies (Verdon, 2017).

\subsection{Advancing Disability Inclusion at the Workplace and in Everyday Life}

According to the American Association of People with Disabilities, seventy-five percent of people with disabilities who are capable of working are either underemployed or not working. People with disabilities were laid off five times faster than people without disabilities in the past ten years. Despite the challenging economic situation that governments have been scrambling to address, many people with disabilities remain unemployed or underemployed, even though workers with disabilities are rated consistently as average or above average according to the U.S. Department of Education. It is high time that the workplace changes its perceptions and provides opportunities for people with disabilities to enter the workforce. This would result in increased economic competitiveness on a global scale (Olson, 2018).

Despite recent positive changes in attitude, it is however no longer enough for a company to simply run through a checklist to make their business accessible and hire people with disabilities, without making them a part of the primary design (Ali, 2017). The unique challenges that individuals with disabilities face requires ingenuity on a daily basis. They know how to adapt and how to look at things outside of the box. By leveraging on their own experiences, they are able to engineer new ways to connect and engage, thus giving way to breakthroughs in their organizations (Olson, 2018). Businesses which have expanded their disability recruitment and hiring efforts have observed that including the perspectives of persons with disabilities in problem-solving leads to novel and better solutions. People with disabilities bring unique talents and skills to the fore that drive creativity and innovation. As people with disabilities move up the organizational ladder and acquire positions of power, they are able to expand client bases and push through changes for people lower in the hierarchy to strengthen their own diversity (Ali, 2017). As a bonus, such workplaces capable of advanc- 
ing the careers of their disabled employees acquire credibility within the disability community.

New York City installed touchscreen kiosks that provided pedestrians with directions, WiFi and phone-charging capabilities, but did not include functionality for people with visual impairments. The irony is that once such problems were revealed, they were quickly resolved with existing technologies such as text-to-speech capabilities. Such problems could be tackled right from the start if the appropriate procurement exercise was carried out. Following a lawsuit of New York City in 2016 by the National Federation of the Blind, the city appointed a commissioner for people with disabilities with a view to modernize the city through the lens of inclusion. People with disabilities must hold positions of influence such as city/infrastructure planners and be embedded in development projects (Minsky, 2020).

\subsection{Usable Design: Disabled Beta Testers}

Another concept closely linked to universal design and inclusive design is usability or usable design. Usability is generally concerned with testing the ease at which users can learn how to operate a product and remember how to do so when they return to the product the following time. These are usually conducted by usability engineers. However, many products that perform well in general usability tests later prove to be non-accessible to people with disabilities (DO-IT, 2021). This is because usability testing related to disability should be more focused on looking out for errors related to accessibility (Deque Systems, 2014). It is regretful that people with disabilities are not always included in usability tests though being part of the user demographic.

Many companies are enlisting the services of disabled individuals to serve as beta testers. In the conception of Mimica Touch, a tactile expiry date made of a biodegradable gel which feels smooth to touch when food is fresh and bumpy when it is bad thus enabling visually impaired people to know when food is out of date, gathering diverse testers with a range of disabilities was key to design (Dawood, 2019). Tactile paving built in India's Visakhapatnam Airport, which warns impaired passengers about obstacles and turns coming ahead, was tested by students from local schools for the blind (Grey, 2018).

An industry undergoing major design rethinking is the textile industry. It has only recently realized that functional clothing for each type of disability has entirely different requirements, e.g. those who are wheelchair bound, those who are bed ridden, autistic persons, etc. The quality of life of people with disabilities can be substantially improved by good looking and functional clothing that would not only ease their daily lives but also help boost their confidence (Meinander \& Varheenmaa, 2002; Ayachit \& Thakur, 2017). Tommy Hilfiger has launched a disability-friendly clothing line called Tommy Adaptive. The campaign to showcase the line included several prominent figures in the disability community, including an autistic chef, a dancer who uses a wheelchair, a Paralympic track-and-field gold medallist and a blogger and motivational speaker 
who has a prosthetic leg. Feedback from the disability community contributed to the Tommy Adaptive line and customer feedback thereafter significantly helped improve the first line (Gallucci, 2018).

In another application of usability, the Society for the Physically Disabled in Singapore runs the Infocomm Accessibility Centre, which houses the first ever-assistive technology loan library in Asia. The library is stocked with more than 700 types of assistive technology equipment which users can borrow to assess their suitability before buying similar equipment (ZD Net, 2011).

\subsection{Innovation for Situational/Physical/Intellectual/Hidden Disabilities}

Situational disability is context driven, whereby a person is unable to carry out a task or activity optimally due to some distracting element. The concept of situational disability remains shrouded in controversy, with some people even judging it as misguided or offensive. Indeed, a person experiencing a situational disability due to some distraction suffers neither the stigma nor the lifelong consequences of exile faced by those suffering from permanent disabilities. However, from a disability innovation perspective, situational disabilities highlight that everyone and anyone sometimes faces limits to their abilities when interacting with dynamic situations, contexts and environments. Situational disabilities have real, even life or death, consequences because people's abilities are significantly diminished by them (Harper \& Yesidala, 2008). For example, a fire in a shopping mall may trigger situational disabilities of varying types and degrees in people: from the local visitor who is blinded by smoke, impaired by the loud fire alarm, restricted in movement by the fleeing crowd, to the language barrier also confusing the foreign visitor on top of everything else, to the cognitive overload of trying to prioritize victims by first responders, to the bulky protective equipment worn by firefighters and finally, the fear/stress/panic felt by everyone (Gjøsæter, Radianti, \& Chen, 2019). Allowing for situational disabilities in design thinking helps to find design solutions that benefit all users and their abilities (Harper \& Yesidala, 2008).

People suffering from Parkinson's disease suffer from hand tremors; people suffering from arthritis may feel muscle weakness or experience limited dexterity. For such people, basic life activities such as eating and drinking can quickly become disabling. HandSteady is a cup, light in weight, designed to help reduce spills when drinking. It is equipped with a rotatable, oversized handle, which makes it easier to tip the cup to drink without having to bend the wrist or lift the arm. The oversized handle additionally allows a person to hold the cup with all four fingers (handSteady, 2021). Spoons have also been customised to ease eating. The Gyenno spoon, with a weighted handle and a good grip, has been shown to electronically reduce tremors by $85 \%$ (Wanja, 2021).

Each year, one million children are born worldwide with a genetic condition, which may degenerate into serious medical complications and ultimately lead to intellectual disabilities if not diagnosed as early as possible. Such rare genetic 
conditions are notoriously difficult to diagnose. However, since around thirty to fifty per cent of these children share facial similarities, clinicians are now hoping to use digital dysmorphology to make earlier detections and deliver timely medical interventions. The University of Queensland, Australia developed an algorithm that matches common facial traits across ethnicity, age and gender and by pairing it with facial recognition software, rare diseases and common genetic disorders can be diagnosed (The University of Newcastle, Australia, 2018). A similar project developed by the Children's National Health System, Washington is currently undergoing clinical validation required for market clearance (Roy, 2018).

Innovation does not always have to involve new technologies; it also entails new ways of looking at disabilities. Approximately 50 million people suffer from dementia globally, with some 10 million new cases being diagnosed yearly. Two years ago, London's Heathrow Airport became the world's first dementia friendly airport when it launched a training program designed to familiarise its 76,000 staff with the syndrome, with particular emphasis on frontline Special Assistance staff (Grey, 2018). Similarly, Delhi Airport in India have successfully trained 900 of its staff in dealing with autistic passengers, who are now directed through a separate security queue. Indian NGO Action for Autism assisted personnel in correctly identifying and handling special needs passengers. This training has been extended to staff in other airports in Mumbai, Bangalore and Kolkata (Sandhu, 2017). Ireland's Shannon Airport became the first European airport to open a sensory room, dedicated to travellers with neurodevelopmental challenges, including autism. Airport staff also organises pre-arranged tours so that passengers can familiarise themselves with their surroundings ahead of their travel day (Grey, 2018).

\subsection{Disability Innovation Assisted by Smart Technology}

Navigating in a wheelchair in urban landscapes can quickly prove to be frustrating and even dangerous. Applications such as Mapp4all allow wheelchair users, blind people, hearing-impaired and others to find out how accessible a building is before they visit it, whether ramps or lifts are available to access a cinema, whether a restaurant provides menus in Braille, etc. BlindSquare and Wayfindr mobile applications offer audio instructions to help blind people navigate cities globally (Thomson Reuters Foundation, 2018).

The hospitality and travel industry stands to gain tremendously by making the thousands of hotels, restaurants and airports more accessible and inclusive for people with disabilities. Loud Steps is a mobile application, serving as a mapping tool, which locates and guides blind and visually impaired people. Recently installed at the DoubleTree by Hilton Hotel Chicago, the app provides step-by-step barrier-free directions using the hotel's floor plans and Wi-Fi to provide audio prompts to help navigate a building's interior, including indoor restaurants and exits in case of an emergency (Hertzfeld, 2018). 
Although many hotels have made provision for special disabled rooms, it is generally accepted that hospitality has not paid enough attention to travellers with disabilities until now. As a result, many disabled guests do not notify their disability when booking a hotel as they do not want to stay in the PRM (people with reduced mobility) room, often considered as too medical. As a result, the PRM room often remains unoccupied (Ting, 2017). Accor Hotels have designed a Smart Room that intends to put an end to the segmentation between the PRM room and other rooms. While the Smart Room was designed to accommodate travellers with reduced mobility, it was created to be a room for everybody, i.e. families, people with disabilities, children and the elderly. The Smart Room includes wardrobes with sliding shelves and rods for easy access, TVs that swivel 180 degrees, adjustable bed heights, bathrooms with easily adjustable shower heads, shower seats, height-adjustable sinks, as well as grab bars that double as towel rails (Ting, 2017).

\section{Status of Disability and Disability Innovation in Mauritius}

\section{Research Findings Based on Observation Research}

The 2011 Population Census conducted by Statistics Mauritius revealed that some 60,000 persons live with some level of disability, out of which $51.6 \%$ were women. Around $1.5 \%$ of disabled persons are under the age of 15 years old. The two most prevalent forms of disabilities are physical disabilities (42\%) and visual impairments (24\%). $20 \%$ of those with a disability have difficulty remembering, concentrating or acquiring education and learning (Statistics Mauritius, 2015). Mauritius signed the United Nation Convention on the Rights of Persons with Disabilities (CRPD) on 25 September 2007 and ratified the document on 8 January 2010 (Budoo, n.d.). A number of disability-inclusive policies have been implemented by the Ministry of Social Security and National Solidarity.

In terms of Disability Innovation, very few companies and non-governmental organisations are truly innovating in the disability field. The Mauritius Research and Innovation Council, operating under the aegis of the Ministry of Technology, Communication and Innovation, is the apex body for the promotion and coordination of Government investment in research and innovation. The MRIC operates a number of research and innovation schemes since 2014, for different target groups ranging from individuals, start-ups to micro, small, medium and large enterprises, including specific schemes catered for academic institutions, research institutions and NGOs. Over 500 applications have been received over the years for funding of innovative projects. However, less than 10 applications have been received in the field of disability innovation and only four projects have been recommended for approval.

Digital Fourteen Ltd (Ipedis Mauritius), a Mauritian company working with its French counterpart, Ipedis France, is involved in rendering PDF reports accessible to the visually impaired. PubliSpeak, developed by Ipedis, is an interactive and fully accessible communication platform for corporate publications 
(annual reports, shareholders' guide, catalogues, press releases, etc.). It also assesses the accessibility of websites and thereafter proposes solutions. It is noted with regret that the clients of Ipedis Mauritius are mostly based abroad, with almost none of the Mauritian big companies making an effort to make their publications or website digitally accessible (Ipedis, 2021; Startup Info Team, 2019).

The Government in its Programme 2015-2019 committed to introduce a Disability Bill in parliament, which would help set up a consolidated disability authority, thus preventing the duplication of services, wasting of resources and unnecessary delays. In January 2021, the Cabinet agreed to the preparation of the Disability Bill by the Attorney General's Office (Bankur, 2020; Prime Minister's Office, 2021). One of the most prominent associations working for the welfare and well-being of persons with disabilities in Mauritius is the Global Rainbow Foundation (Global Rainbow Foundation, 2021). To be proactive, a draft bill was presented by the Global Rainbow Foundation in February 2021. Once relevant suggestions from all stakeholders are considered, the association hopes that the Disability Bill will finally be brought to parliament.

\section{Conclusion}

Refreshing changes in attitude towards people with disabilities due to innovation are already being witnessed. When a French boy, Maxènce, was fitted with the first three-dimensional printed hand in the world (a wearable device instead of undergoing a surgical procedure), he was looked upon as a hero by other kids at school (Sogeti Labs, 2015). Indeed, there is a need to keep the momentum going so that more innovative solutions are devised to help people with temporary or permanent disabilities and people finding themselves in situational disability.

Disability innovation should serve as a clarion call for organisations to recognise that in order to cultivate a competitive advantage, they must be ready to integrate disability as a critical component of not only their foundational business strategy but also an essential piece in developing a pathway to innovation. People with disabilities represent a vast market that is often overlooked and largely untapped. Both established companies and new innovative startups need to be on the lookout for opportunities in disability or think of the future of their current products and services with disability lens in mind. Incentives should also be given to people affected by disabilities to themselves create solutions to challenges they face in their daily lives. Moreover, if product designers apply universal design principles, keeping in mind accessibility for people with disabilities, and if usability engineers make sure to include people with a variety of disabilities in usability tests as beta testers, more products will be accessible to and usable by everyone (DO-IT, 2021).

On a final note, while the advent of technology has inevitably led to innovation in disability and will continue to do so, disability innovation should not be solely anchored to technology. Any initiative, however small or big, is welcomed 
as attested by the one undertaken by Pune International Airport in India. The artwork of painter Chintamani Hasabnis was exhibited there and had the particularity of being filled with tactile outlines and borders, with descriptions written in Braille. This was lauded by those who can see and who cannot, alike (Ambedkar, 2018). The time for disability innovation is now.

\section{Acknowledgements}

The author is thankful to Mr. Jackir Assan Ally, co-founder of Ipedis for his time and insightful comments. With the publication of this perspective, the author hopes to contribute positively to the debate around a Disability Bill which the Mauritian Government has committed to bring to the Mauritian parliament for vote. The author also hopes to inspire Mauritian companies and institutions to innovate in the field of disability.

\section{Conflicts of Interest}

The views and opinions expressed in this article are those of the author and do not necessarily reflect the policy or position of the Mauritius Research and Innovation Council as an organisation. The author declares no conflict of interest with respect to the research, authorship and/or publication of this article.

\section{References}

Ali, A. (2017, July 19). Inclusive Design at the Disability Innovation Summit. https://www.sutherlandlabs.com/blog/inclusive-design-disability-innovation-summit/

Ambedkar, S. (2018, January 19). Artist's Visual Artwork at Pune Airport Gives Eyes to the Blind.

https://punemirror.indiatimes.com/pune/civic/artists-visual-artwork-at-pune-airport-g ives-eyes-to-the-blind/articleshow/62560610.cms

Aruma (2021a). Types of Intellectual Disabilities.

https://www.aruma.com.au/about-us/about-disability/types-of-disabilities/types-of-int ellectual-disabilities/

Aruma (2021b). Types of Physical Disabilities.

https://www.aruma.com.au/about-us/about-disability/types-of-disabilities/types-of-ph ysical-disabilities/

Aruma (2021c). Types of Sensory Disabilities.

https://www.aruma.com.au/about-us/about-disability/types-of-disabilities/types-of-sen sory-disabilities/

Ayachit, S., \& Thakur, M. (2017). Functional Clothing for the Differently Abled. Indian Journal of Public Health Research \& Development, 8, 904-913.

Bankur, A. (2020, December 3). International Day of Persons with Disabilities: Why the Need for a Disability Bill.

https://www.lemauricien.com/le-mauricien/december-3-international-day-of-personswith-disabilities-why-the-need-for-a-disability-bill/390894/

Budoo, A. (n.d). Mauritius: Updated Country Report. Repository on Disability Rights in Africa.

http://www.rodra.co.za/index.php/countries/mauritius/23-countries/mauritius/63-mau $\underline{\text { ritius }}$ 
Challenge America (2019, February 7). Meet the Veterans Who Will Inspire New Innovations This Spring.

https://www.challengeamerica.com/blog-2/camvets-cleveland-veteran-challengers

Daehn, I. S., \& Croxson, P. L. (2021). Disability Innovation Strengthens STEM. Science, 373, 1097-1099. https://doi.org/10.1126/science.abk2631

Dawood, S. (2019, May 21). How to Make Packaging More Accessible. https://www.raconteur.net/sustainability/inclusive-design-packaging

Deque Systems (2014). How to Incorporate Users with Disabilities in UX Testing. https://www.deque.com/blog/incorporate-users-disabilities-ux-testing/

Disability Innovation (2021a). Disability Innovation for a Fairer World. https://www.disabilityinnovation.com/

Disability Innovation (2021b). MSc Disability, Design and Innovation at UCL. https://www.disabilityinnovation.com/education/msc-ddi

Disability Innovation Institute (2021). https://www.disabilityinnovation.unsw.edu.au/

Disabled World (2021, August 15). Invisible Disabilities: List and General Information. https://www.disabled-world.com/disability/types/invisible/

DO-IT (Disabilities, Opportunities, Internetworking, and Technology). (2021, April 9). What Is the Difference between Accessible, Usable, and Universal Design? https://www.washington.edu/doit/what-difference-between-accessible-usable-and-univ ersal-design

Gallucci, N. (2018, April 6). Tommy Hilfiger Unveils Innovative Clothing Line for People with Disabilities.

https://mashable.com/2018/04/06/tommy-hilfiger-tommy-adaptive-disibility-friendly-c lothing/\#pqUAepqBYkqV

Gjøsæter, T., Radianti, J. \& Chen, W. (2019). Understanding Situational Disabilities and Situational Awareness in Disasters. In: Z. Franco, J. J. González, \& J. H. Canós (Eds.), Proceedings of the 16th International Conference on Information Systems for Crisis Response and Management [ICSCRAM 2019, València, Spain, May 2019] (pp. 940-949). ICSCRAM Association.

Global Rainbow Foundation (2021). Advocacy of Global Rainbow Foundation (GRF). https://grftrust.org/advocacy/

Goggin, G. (2008). Innovation and Disability. M/C Journal, 11. https://doi.org/10.5204/mcj.56 http://journal.media-culture.org.au/index.php/mcjournal/article/view/56

Grey, E. (2018, February 13). Smart Environments: How Airports Use Tech to Welcome Special Needs Passengers.

https://www.airport-technology.com/features/smart-environments-airports-use-tech-w elcome-special-needs-passengers/

handSteady (2021). Introducing handSteady ${ }^{\oplus}$ : The Safe and Natural Way to Drink Easier again. https://handsteady.com/en/

Harper, S., \& Yesilada, Y. (2008). Web Accessibility: A Foundation for Research (Human-Computer Interaction Series). Springer-Verlag.

https://doi.org/10.1007/978-1-84800-050-6

Hertzfeld, E. (2018, April 3). App for Visually Impaired Debuts at Chicago-Area DoubleTree by Hilton.

https://www.hotelmanagement.net/tech/app-for-visually-impaired-debuts-at-doubletre e-by-hilton-illinois 
Ipedis.com. (2021). Digital Accessibility Definition.

https://www.ipedis.com/en/digital-accessibility-definition

Jain-Link, P., \& Taylor Kennedy, J. (2019, June 3). Why People Hide Their Disabilities at Work. https://hbr.org/2019/06/why-people-hide-their-disabilities-at-work

Mace, R. (1985). What Is Universal Design? https://universaldesign.org/definition

Meinander, H. \& Varheenmaa, M. (2002). Clothing and Textiles for Disabled and Elderly People (Research Notes No. 2143). VTT TIEDOTTEITA. https://www.vttresearch.com/sites/default/files/pdf/tiedotteet/2002/T2143.pdf

Minsky, C. (2020, January 29). Better Data Paves the Way for Improved Accessibility. https://www.ft.com/content/76341a64-1c3d-11ea-81f0-0c253907d3e0

Neves-Charge, H. (2017). Inclusive Design: It's Your Job. https://medium.com/valtech-design/inclusive-design-dd4e03f82094

Olson, M. (2018). Letter: Time to Hire People with Disabilities. https://www.swnewsmedia.com/chaska herald/news/opinion/letters to the editor/lett er-time-to-hire-people-with-disabilities/article 75f3a384-b7b9-5d69-905d-7a4c1fde23e c.html

Paudel, S., Bhandari, L. and Bhandari, D. (2017) Disability: A Case Screening Program Approach. Journal of Biosciences and Medicines, 5, 10-21. https://doi.org/10.4236/jbm.2017.52002

Prime Minister's Office (2021). Cabinet Decisions - 22 January 2021. https://pmo.govmu.org/CabinetDecision/2021/Cabinet\%20Decisions taken on $22 \% 2$ 0January\%202021.pdf

Rose, Z. (2016, May 19). The Biggest Driver of Innovation You've Never Heard of. https://www.digitalpulse.pwc.com.au/universal-design-disability-global-accessibility-da yl

Roy, S. (2018, April 3). Pediatricians Are Now Using Facial Recognition on Babies. https://techwireasia.com/2018/04/pediatricians-are-now-using-facial-recognition-on-b abies/

Sandhu, K. K. (2017, September 8). CISF Deployed at Delhi Airport Becomes Autistic Friendly Force. India Today. https://www.indiatoday.in/fyi/story/delhi-airport-cisf-deployed-autistic-friendly-forceperson-with-disabilities-1082309-2017-11-08

Sogeti Labs (2015). When Innovation Changes the Meaning of Disability. https://labs.sogeti.com/when-innovation-changes-the-meaning-of-disability/

Startup Info Team (2019). Ipedis propose des outils d'accessibilité numérique pour les personnes handicapées. https://startup.info/fr/publispeak/

Statistics Mauritius. (2015). 2011 Housing and Population Census. Analytical Report Volume VII-Disability. Ministry of Finance and Economic Development. https://statsmauritius.govmu.org/Documents/Census and Surveys/HPC/2011/HPC A R Vol7 Disability Report Yr11.pdf

Steenhout, N. (2018). The Evolution of Assistive Technology into Everyday Products. https://incl.ca/the-evolution-of-assistive-technology-into-everyday-products/\# Toc270 $\underline{431673}$

The University of Newcastle, Australia (2018, April 4). Finding a FaceMatch Could Unlock Genetic Puzzles.

https://www.newcastle.edu.au/newsroom/featured/finding-a-facematch-could-unlockgenetic-puzzles 
Thomson Reuters Foundation (2018, April 19). Access All Areas? Using Data to Disabled Navigate Cities. The Jordan Times.

http://jordantimes.com/news/features/access-all-areas-using-data-disabled-navigate-cit ies

Ting, D. (2017, November 22). AccorHotels Is Working on a Smart Room That's Accessible and Personalized. Skift.

https://skift.com/2017/11/22/accorhotels-is-working-on-a-smart-room-thats-both-acce ssible-and-personalized/

UN (United Nations) (2021). Factsheet on Persons with Disabilities. https://www.un.org/development/desa/disabilities/resources/factsheet-on-persons-with -disabilities.html

Verdon, N. (2017). Why Are Smart Investors Missing the Opportunities Available in Disability Innovation? https://www.briometrix.com/calls-for-disability-innovation/

Wanja, T. (2021, December 2). Smart and Weighted Parkinson's Spoons Review: A Look at Anti Tremor Cutlery for People with PD and Essential Tremors in 2021. https://hosiped.com/parkinsons-spoon/?cn-reloaded=1\&cn-reloaded=1

Wise, P. H. (2012). Emerging Technologies and Their Impact on Disability. The Future of Children, 22, 169-191. https://doi.org/10.1353/foc.2012.0002

Wolbring, G. (2011). Differences Matter: Innovations and People with Disabilities. https://www.federationhss.ca/en/blog/differences-matter-innovations-and-people-disa $\underline{\text { bilities }}$

Young Marr Law (2021). The Difference between Temporary Disability and Permanent Disability.

https://www.youngmarrlaw.com/the-difference-between-temporary-and-permanent-di $\underline{\text { sability/ }}$

ZD Net (2011, August 29). Enabling the Disabled with Tech. https://www.zdnet.com/article/enabling-the-disabled-with-tech/ 